\title{
Lob der Vielseitigkeit
}

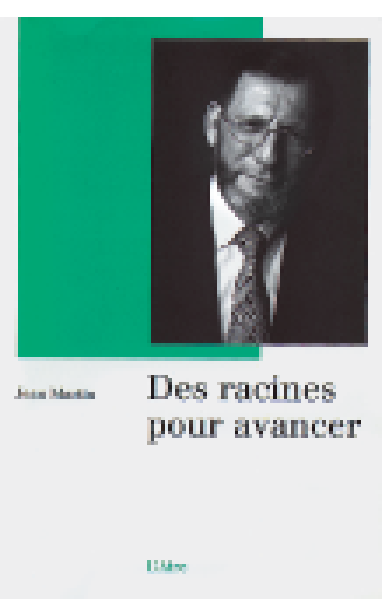

Jean Martin. Des racines pour avancer. Vevey: Editions de l'Aire; 2005. 327 Seiten. ISBN: 2-88108-752-3
Im Mittelalter gab es sie noch: die Universalgelehrten, Menschen, die das gesamte Wissen ihrer Zeit beherrschten und hoch angesehen waren. Diese Zeiten sind längst vorbei. Die exponentielle Wissensvermehrung der Neuzeit hat zwangsläufig zum Aufschwung des Spezialistentums geführt, der - vielleicht nicht ganz so zwangsläufig - mit einer Verringerung der Wertschätzung des Generalistentums einherging. Was die Medizin betrifft, befinden sich die Patienten diesbezüglich häufig in einer Zwickmühle: Wenn sie auch dem Spezialisten als Fachmann vertrauen und seine Behandlung gern beanspruchen, so beklagen sie mitunter doch seinen eingeengten Blickwinkel, bei jüngeren Kollegen auch mal den «Mangel an allgemeiner Lebenserfahrung». Ob dies zu Recht geschieht, bleibe dahingestellt.

Vor diesem Hintergrund sind «Gegenbeispiele» interessant: Ärzte, die sich durch Vielseitigkeit auszeichnen und gleichzeitig hohes Ansehen geniessen. Jean Martin, ehemaliger Kantonsarzt der Waadt, Privatdozent, Publizist und unter anderem Verwaltungsratsmitglied des Schweizerischen Ärzteverlags, zählt unzweifelhaft zu dieser Kategorie. Zu verifizieren ist diese Aussage in seinem jüngsten Buch «Des racines pour avancer» ${ }^{*}$, in dem er fesselnde Einblicke in seinen Werdegang und seine Sicht der Welt gewährt.

Verwurzelt im waadtländischen Winzermilieu, aus einem engagiert-christlichen Elternhaus stammend, ist Martin den ihm vermittelten Grundwerten treu geblieben, gleichzeitig aber mit grosser Offenheit und Neugier in die Welt hinausgezogen. Wobei der Begriff Welt in seinem Fall durchaus umfassend zu verstehen ist. Die Anzahl der Länder und Regionen der Erde, die er aus eigener Erfahrung kennt, ist beeindruckend, und seine Kenntnisse sind weit von oberflächlichen Urlaubserfahrungen entfernt. So arbeitete er unter anderem als Arzt in der peruanischen «Selva», in Indien und in Kamerun, wobei sich einzelne Aufenthalte über mehrere Jahre erstreckten. Nicht von ungefähr zitiert er deshalb zum Auftakt eines Kapitels Aristophanes: «Où l'on est bien, là est la patrie.»
Eingetaucht ist Jean Martin aber auch mit Leidenschaft in die Welt der Kunst im allgemeinen und der Literatur im speziellen, der Philosophie und der Wissenschaftstheorie. Seine diesbezüglichen Interessen mündeten in ein starkes Engagement in Fragen der Ethik, etwa als Mitglied der Nationalen Ethikkommission. Überhaupt sind Praxisbezogenheit und Erdverbundenheit kennzeichnend für ihn, der sich auch beruflich als Kantonsarzt und als Parlamentarier in seinem Heimatkanton intensiv mit den Anliegen und Problemen der Bevölkerung befasst.

Wenn er sich selbst die «Mentalität eines Langstreckenläufers» attestiert, so muss diese Einschätzung zutreffend sein. Anders als mit einer solchen Mentalität wäre die Vielzahl der Aufgaben, auf die er sich eingelassen hat und immer noch einlässt, wohl nicht zu bewältigen. Nach dem bisher Gesagten wird es kaum überraschen, dass auch dieses Attribut mehr als Metaphorik ist: Martin ist tatsächlich auch Langstreckenläufer; er hat unter anderem den New York Marathon, den 100-km-Lauf von Biel und den Berglauf Sierre-Zinal absolviert. Der Durchhaltewille, den er dabei an den Tag legen musste, dürfte ihm im zähflüssigen politischen und kantonsärztlichen Alltag bei der Umsetzung seines Credos zugute gekommen sein: «Rendre possible le nécessaire.»

Es ist müssig, in diesem Rahmen all die weiteren Mosaiksteinchen aufzählen zu wollen, die sich im Buch zum «Selbstporträt» von Jean Martin zusammenfügen. Die gewählte Form der thematisch geordneten Zusammenstellung kürzerer Artikel und Essays zu einem Buch von mehr als 300 Seiten hat den Vorteil, dass man sich als Leser gewissermassen nach dem Lustprinzip häppchenweise bedienen kann und so über die Zeit ein facettenreiches Gesamtbild erhält. Als Schwäche könnte der fehlende «Zug», der sich aus der fragmentarischen Form ergibt, gewertet werden. Doch keine Sorge: Den bringt ein Autor, der es schafft, seine Wurzeln als Mittel zur Fortbewegung zu nutzen, durchaus in sein Werk.

Bruno Kesseli 